\title{
Simulation of Peroxiredoxin II and Brain-type Creatine Kinase protein-protein interaction using the on-line docking server ClusPro 2.0
}

\author{
Anar Rakhmetov ${ }^{1 *}$, Sang Pil Lee ${ }^{2}$, Dmytro Grebinyk ${ }^{1}$, Ludmila Ostapchenko $^{1}$, Ho Zoon Chae ${ }^{2}$ \\ ${ }^{1}$ Education and Science Center Institute of Biology Taras Shevchenko National University of Kyiv, Glushkova Ave., 2, 03022, Kyiv, Ukraine. \\ ${ }^{2}$ Chonnam National University, School of Biological Science and Technology, 77 Yongbong-ro, Buk-gu, 500-757, Gwangju, South Korea.
}

\begin{tabular}{|c|c|}
\hline ARTICLE INFO & ABSTRACT \\
\hline Article history: & \multirow{9}{*}{$\begin{array}{l}\text { Importance of dedicated web servers and specialized software for simulations of protein-protein interactions is } \\
\text { well established. The purpose of our study was to examine the protein-protein interaction that occurred under } \\
\text { physiological and stress conditions between peroxiredoxin II and the creatine kinase brain-type using protein- } \\
\text { docking server ClusPro } 2.0 \text {. To predict the particular site of amino acid docking, computer software analyzes } \\
\text { various protein conformations and chooses the most profitable energy state, therefore selecting a number of } \\
\text { possible combinations that would fit the correct profile. By co-immunoprecipitation assay, we demonstrated that } \\
\text { two molecules Prx II and CKBB have interacted with further attenuation of this specific binding by pretreatment } \\
\text { with selected stress factors. In previous study, we showed that the enzymatic activity of CKBB was recovered by } \\
\text { different concentration ratios of Prx II. The specific binding models were generated by ClusPro } 2.0 \text { protein } \\
\text { docking server and studied using PyMol software. It was shown that a number of amino acid residues including } \\
\text { Lys } 11 \text {, Arg 13, Ala 204, Arg } 209 \text { for creatine kinase, and Asp } 181 \text {, Glu 192, Lys } 196 \text {, Glu 162, Gln } 163 \text { for Prx II } \\
\text { have participated in the complex formation throughout the first ten conformations. }\end{array}$} \\
\hline Received on: $28 / 04 / 2015$ & \\
\hline Revised on: $17 / 05 / 2015$ & \\
\hline Accepted on: 22/06/2015 & \\
\hline Available online: $28 / 08 / 2015$ & \\
\hline $\begin{array}{l}\text { Key words: } \\
\text { peroxiredoxin II, creatine }\end{array}$ & \\
\hline & \\
\hline neurodegenerative disorders & \\
\hline & \\
\hline
\end{tabular}

\section{INTRODUCTION}

Mammalian peroxiredoxin II (Prx II, EC 1.11.1.15) with two conserved cysteine residues is a member of peroxiredoxin antioxidant family that eliminates endogenous hydrogen peroxide and exhibits chaperonic activity towards target proteins (Schroder et al., 2000; Jang et al., 2004). Peroxiredoxin II belongs to the typical 2-Cys Prx subfamily, where the basic active unit is a homodimer, with catalytically active disulfide bond formed between two subunits with peroxidatic $\left(\mathrm{C}_{\mathrm{P}}\right)$ and reducing $\left(\mathrm{C}_{\mathrm{R}}\right)$ cysteins (Rhee and Woo, 2011; Hall et al., 2009). Sulfenic acid $\mathrm{Cys}-\mathrm{S}_{\mathrm{P}} \mathrm{OH}$ that generated in a result of neutralization of peroxide molecule reduced to its normal active state by the thioredoxin family proteins (Hanschmann et al., 2013; Hall et al., 2011). However, rapid

\footnotetext{
* Corresponding Author

Anar Rakhmetov, Education and Science Center Institute of Biology

Taras Shevchenko National University of Kyiv, Glushkova Ave., 2,

03022, Kyiv, Ukraine. Email: anar.rakhmetov@gmail.com
}

disulfide formation can be impeded by the distance between the sulfur atoms of $C_{P}$ and $C_{R}(13 \AA)$ what thought to be a substantial obstacle for rapid disulfide formation (Hirotsu et al., 1999).Thus, further hyperoxidation of $\mathrm{C}_{\mathrm{P}}-\mathrm{SOH}$ to protein sulfinic acid $\mathrm{C}_{\mathrm{P}}-\mathrm{SO}_{2} \mathrm{H}$ is possible. During this type of catalytic hyperoxidation, the Prx II overcomes a structural transition from a homodimer to a doughnutshape decamer, and aggregated form of the enzyme gains protein chaperone activity (Moon et al., 2005).

On the other hand, creatine kinase $(\mathrm{CK}$, creatine $\mathrm{N}$ phosphatransferase, EC 2.7.3.2), as the cytoplasmic forms of phosphagen kinases, has a conventional dimeric structure consisting of two identical $42 \mathrm{kDa}$ subunits (Tanaka and Suzuki, 2004). CK catalyzes the reversible reaction of phosphocreatine formation $(\mathrm{P} / \mathrm{Cr}$ )with consequential ATP consumption. Generated $\mathrm{P} / \mathrm{Cr}$, therefore will be used to regenerate ATP molecule during the energy depletion (Wallimann et al., 2011). Cytosolic brain-type creatine kinase (CKBB) is a one of three CK enzyme isoforms that mainly expressed in brain, spermatozoa, kidney, and retina. 
This enzyme plays a crucial role in energy supplementation of the brain tissue, decrease of its functional activity is one of the biochemical markers of the CNS cell damage in age-related neurodegenerative disorders, including $\mathrm{AD}$, and Huntington diseases (Hensley et al., 1995; Aksenov et al., 1998; Aksenova et al., 1999; Kim et al., 2010).

The crystal structure of CKBB combined with the ADP$\mathrm{Mg}^{2+}-\mathrm{NO}^{3-}$ creatine transition-state analogue was resolved by Bong laboratory. The study presented that negatively charged aminoacid residues are responsible for substrate binding in the active site of CKBB (Asp, Arg, Glu).Hydrophobic interaction are the primary interaction within the molecule. Five positively charged Arg residues are composing the phosphate-binding pocket of CKBB (Bong et al., 2008). Whereas, the first crystallographic study of decameric Prx II has been completed on the protein purified from human erythrocytes (Schroder et al., 2000). The study has determined that the structure is a toroid, comprising of five dimers linked predominantly by hydrophobic interactions. The monomer subunit of Prx II homodimer comprised of domain I (residues 2-169) and a C-terminal arm (residues 170-198). The dimer configuration of peroxiredoxin II is organized by two intertwined monomer with the C-terminal arm of one subunit folds over domain I of the other monomer (Schroder et al., 2000).

Automated docking server ClusPro 2.0 was implemented to predict possible interaction sites between Prx II and CKBB proteins. ClusPro 2.0 is a web server that filters docked conformation with good surface complementarity, therefore selects complexes with lowest desolvation and electrostatic energies (Comeau et al., 2004). Methods of computational protein docking generally yield near-native structures however due to the reasons of the intrinsic uncertainty they are far from the native complexes. Therefore, were introduced new approaches that evaluate docked structures based on the chemical affinity between the molecules (Camacho et al., 2000; Norel et al., 2001; Comeau et al., 2004). Filtering algorithm of ClusPro 2.0 include the use of empirical free energy evaluation methods that select the conformations with the lowest desolvation and electrostatic energies (Comeau et al., 2004).

Results from CAPRI (Critical Assessment of Predicted Interaction) experiment have demonstrated that the automatic protein docking server ClusPro 2.0 was the best in the server category. This means that the results generated by ClusPro 2.0 on predicting protein interaction sites are comparable to that of the top human predictor groups (Kozakov et al., 2013).

Recent proteomic studies revealed that members of peroxiredoxin family Prx I and Prx II have numerous target proteins in vitro (Rhee and Woo, 2011). Prx I interacts with apoptosis signal-regulating kinase 1 (ASK1), the Myc box II domain of c-Myc, macrophage migration inhibitory factor (MIF) etc.; where Prx II was identified as a partner of cyclin dependent kinase 5 (Cdk5), and associated with platelet-derived growth factor (PDGF) (Kim et al., 2008; Jung et al., 2001; Mu et al., 2002; Qu et al., 2007; Choi et al., 2005). Computer simulation of the complex formed between Prx I and Srx have demonstrated that the essential substrate of Srxunder physiological conditions is likely to be HMW species of Prx I (Lowther and Haynes, 2011).

Here we confirm with protein-docking software interaction of two proteins, what were identified previously by the immunoprecipitation assay: human brain-type creatine kinase (CKBB) and peroxiredoxin II (Prx II).By the same example of Prx II overexpression in Alzhiemer's disease and protection of neuron cell from amyloid- $\beta$-peptide toxicity (Yao et al., 2007), we can speculate on importance of Prx II to prevent deterioration effects of hydrogen peroxide on CKBB.

\section{MATERIALS AND METHODS}

\section{Target Sequences}

The protein structures of Peroxiredoxin II and Brain-type creatine kinase (CKBB) were publicly available. The complete aminoacid sequences of human Peroxiredoxin II $22 \mathrm{kDa}$ molecule, which consist of 198 amino acids, and human Creatine kinase btype42 kDa molecule with 381 amino acids, were retrieved from RCSB Protein Databank (Prx II - 1QMV; CKBB - 3B6R). Protein structure analyzing was performed with the Expasy'sProtPram Proteomic server (Gasteiger et al., 2005)

\section{Assay conditions}

The creatine kinase b-type was heat inactivated at $42 \mathrm{C}$ in a solution contained $30 \mathrm{nM}$ CKBB and different molar concentrations $(1: 1,1: 5,1: 10,1: 20)$ of Prx II protein. Everything was diluted in a $5 \mathrm{mM}$ Glycine- $\mathrm{NaOH}(\mathrm{pH} 9.0)$ buffer. Aliquots $(60 \mu \mathrm{l})$ were removed at specific time intervals to determine CK activity. The activity measurements were made after a brief preincubation of heat treated samples on ice. Measurements of creatine kinase activity were conducted in accordance with (Yao et al., 1982) with minor modifications (Rakhmetov et al., 2015). Hydrogen peroxide inactivation was established by adding $\mathrm{H}_{2} \mathrm{O}_{2}$ at final concentration of $1 \mathrm{mM}$ to the samples containing the same assay mixture used for thermal inactivation of $\mathrm{CK}$ enzyme. Residual activity was measured at the $597 \mathrm{~nm}$ by adding sample aliquots $(60 \mu \mathrm{l})$ to the reaction mixture with final volume of 600 $\mu 1$.

\section{Molecular docking}

To investigate the molecular interaction between human peroxiredoxin II and the brain-type creatine kinase rigid protein docking was performed using ClusPro 2.0. Within this server enclosed three computational steps that include: rigid body docking using the FFT (Fast Fourier Transform) correlation approach, RMSD (Root Mean Square Deviation) based clustering of the structures generated to find the largest cluster that will represent the likely models of the complex, and refinement of selected structures (Kozakov et al., 2013). By default server settings ClusPro 2.0 simultaneously generates four types of models using the scoring algorithms called designated as balanced, electrostatic-favored, hydrophobic-favored, and van der Waals + electrostatic. We selected the first ten docking structureswith the 
relative low energies that were scored by the server. According to (Kozakov et al., 2013) the only refinement currently applied in CluPro 2.0 is minimizing the Charm energy.

PyMol software was used for visual representation and assessing of the complex interaction, measuring of the distances between the interacting aminoacid residues. By using the multifaceted molecular software were rendered cartoons and surfaces of the docking Prx II decamer and CKBB dimer.

\section{RESULTS AND DISCUSSIONS}

Peroxidase enzymes peroxiredoxins exhibit negligible catalytic activity toward neutralizing metabolic hydrogen peroxide compare to the major $\mathrm{H}_{2} \mathrm{O}_{2}$ scavengers like catalyze, and superoxide dismutase (SOD) (Hanschmann et al., 2013). Therefore, they may play a major role as chaperone molecules. Chaperone function of ubiquitous peroxiredoxin enzymes is well recognized (Moon et al., 2005; Saccoccia et al., 2012), however some functional aspects of the structural organization remain to be elucidated.

It is established that protein structures consist of specific geometric arrangements of the secondary structure elements (Tsai et al., 1997). Some of the motifs of the $\alpha$-helixes and of the $\beta$ sheets have specific associated biological functions. The solvent exposed parts of these motifs are typically hydrophilic and the interiors are hydrophobic with the limited number of special arrangements. Peroxiredoxin II inactivated by hyperoxidation of its cysteine active sites is reversibly capable of transformation from a peroxidase to a high molecular weight chaperone (Lowtherand Haynes, 2011). The substantial structural change of Prx II is associated with disulfide bond formation within the dimeric structure of the enzyme, therefore the peroxiredoxin molecule predominantly cycles between dimeric and decamericoligomeric states.

Here we have utilized a dataset of stable interfaces of human peroxiredoxin II and creatine kinase b-type derived from the PDB database. ClusPro2.0 is aprotein docking server that comparable to GRAMM-X, ZDOCK, RossetaDock, SymmDockand PatchDock. Models built by ClusPro2.0 have been reported in over 200 publications (Kozakov et al., 2013).Several interaction models of Prx II and CKBB were yielded during a simulation run on the ClusPro 2.0 protein docking webserver, with the first model presented (Fig 1.). Processing of these generated models by the molecular graphic software PyMolhas allowed us to outline the most important aminoacid residues that participated in the interaction of two proteinsPrx II and CKBB. As a result, we showed that the C-terminal residue Lys ${ }^{196}$ of Prx II, involved in stabilization of the $\mathrm{COOH}$ terminal domain, has formed a hydrogen bong interaction with the $\mathrm{Ala}^{204}$ aminoacid residue of creatine kinase (Fig.2. A).

Reversible phosphorylation of Prx II induces temporal inactivation of the peroxidase activity, therefore allowing the transient accumulation of $\mathrm{H}_{2} \mathrm{O}_{2}$ for receptor signaling. According to our results the $\mathrm{Asp}^{181}$ residue that forms possible hydrogen bond with $\mathrm{His}^{197}$ to prevent phosphorylation of Prx II (Rhee and Woo, 2011), also participates in the interaction with $\mathrm{Lys}^{11}$ residue of CKBB (Fig. 2. C). Thus, adding the second hydrogen bond to strengthen thePrx II-CKBB protein association.

The salt bridge network that includes Asp ${ }^{181}$ and Lys ${ }^{196}$ with interatomic distance at $2.64 \AA$ and that between $\mathrm{Asp}^{181}$ and $\mathrm{His}^{197}$ at $2.69 \AA$ might stabilize the $\mathrm{COOH}$ terminal domain of Prx II (Rhee and Woo, 2011).Arg 95 is the key residue for guanidine substrate recognition for both $\mathrm{AK}$ and CK enzymes (Uda and Suzuki, 2004; Edmiston et al., 2001).

The monomer of creatine kinase includes an essential $\mathrm{N}$ terminal region with 1-100 aminoacid residues and a $\mathrm{C}$-terminal $\alpha / \beta$ domain, residues $125-381$ both connected with a long linker, residues 101-124 (Bong et al., 2008). According to our simulation results, the top model that possesses the lowest RMSD (Root Mean Square Deviation is the square root of the mean of the square of the distance between the matched atoms) has aminoacid residues that positioned at the beginning of $\mathrm{N}$-terminal region $\left(\mathrm{Arg}^{13}, \mathrm{Asp}^{18}\right)$ and in the middle of C-terminal $\left(\mathrm{Arg}^{209}, \mathrm{Ala}^{204}\right)$. Hyperoxidizedhuman Prx II (monomer $\sim 22 \mathrm{kDa}$, decamer $\sim 220$ $\mathrm{kDa}$ ), presumably forming dodecameric structural units with oxidized cysteine to the sulfinic form (Wood et al., 2003), interacts with the dimeric creatine kinase $(84 \mathrm{kDa})$, thus recovering the enzyme activity. Potential interaction suggested by the model include electrostatic hydrogen bond, CKBB $\mathrm{Ala}^{204}$ with Prx II Lys ${ }^{196}$, as well as electrostatic interaction, CKBB $\mathrm{Arg}^{209}$ with Prx II Glu ${ }^{192}$ (Fig.2, A, B)

Protein folding accompanied by a conformational freedom of the aminoacid chain allows almost any possible protein configuration. This is not the case for protein binding. The rotational and translational packing available to the chains includes only 6 degrees of freedom (Chen and $\mathrm{Xu}, 2003$ ). The individual contribution of amino acids that compose the side chain of interacting proteins can be investigated experimentally by mutating the amino acid of interest with implementation of the site-direct mutagenesis technique (Tsai et al., 1997).

Prominent residue that we registered throughout examination of 20 docked poses was $\operatorname{Arg}^{13}$ of creatine kinase. Unequivocal role for arginine residues from rabbit muscle CK in complete inactivation accompanied by the loss of nucleotide binding was previously established (Wood et al., 1998). In addition, the chemical modification of two arginine residue per mitochondrial creatine kinase monomer showed strong negative co-operatively and complete inactivation of Mi-CK (Belousovaand Muizhnek, 2004).

In our experimental docking the $\mathrm{Arg}^{13}$ residue of CKBB demonstrated prominent interaction with aminoacid residues of peroxiredoxin II moleculeat attained the stable distances of 1.70 , $1.90 \AA$ in the entire simulation period (Fig. 3). Our simulation docking approach has yielded the following aminoacid residues of Prx II molecule that interacted with $\mathrm{Arg}^{13}$ of CKBB: $\mathrm{Glu}^{167}, \mathrm{Gln}^{163}$, $\mathrm{Lys}^{67}, \mathrm{Asp}^{64}, \mathrm{Asn}^{60}$. These hydrogen bond interactions with attained intermolecular distances along with the salt bridge stabilized the protein-protein association the most. 


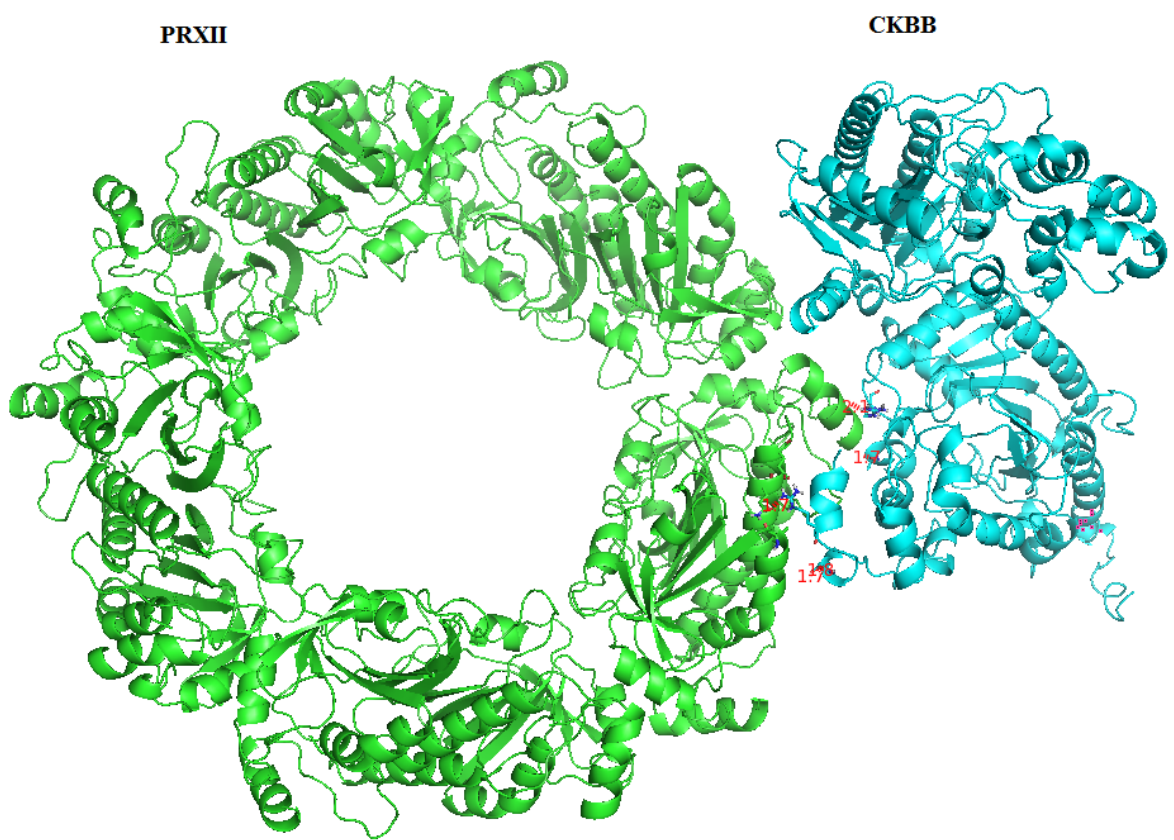

Fig. 1. Ribbon diagram of human decamericPrx II (green) and dimeric CKBB (cyan). DecamericPrx II composed of five dimeric molecules. Outline black square indicates on the interacting region.
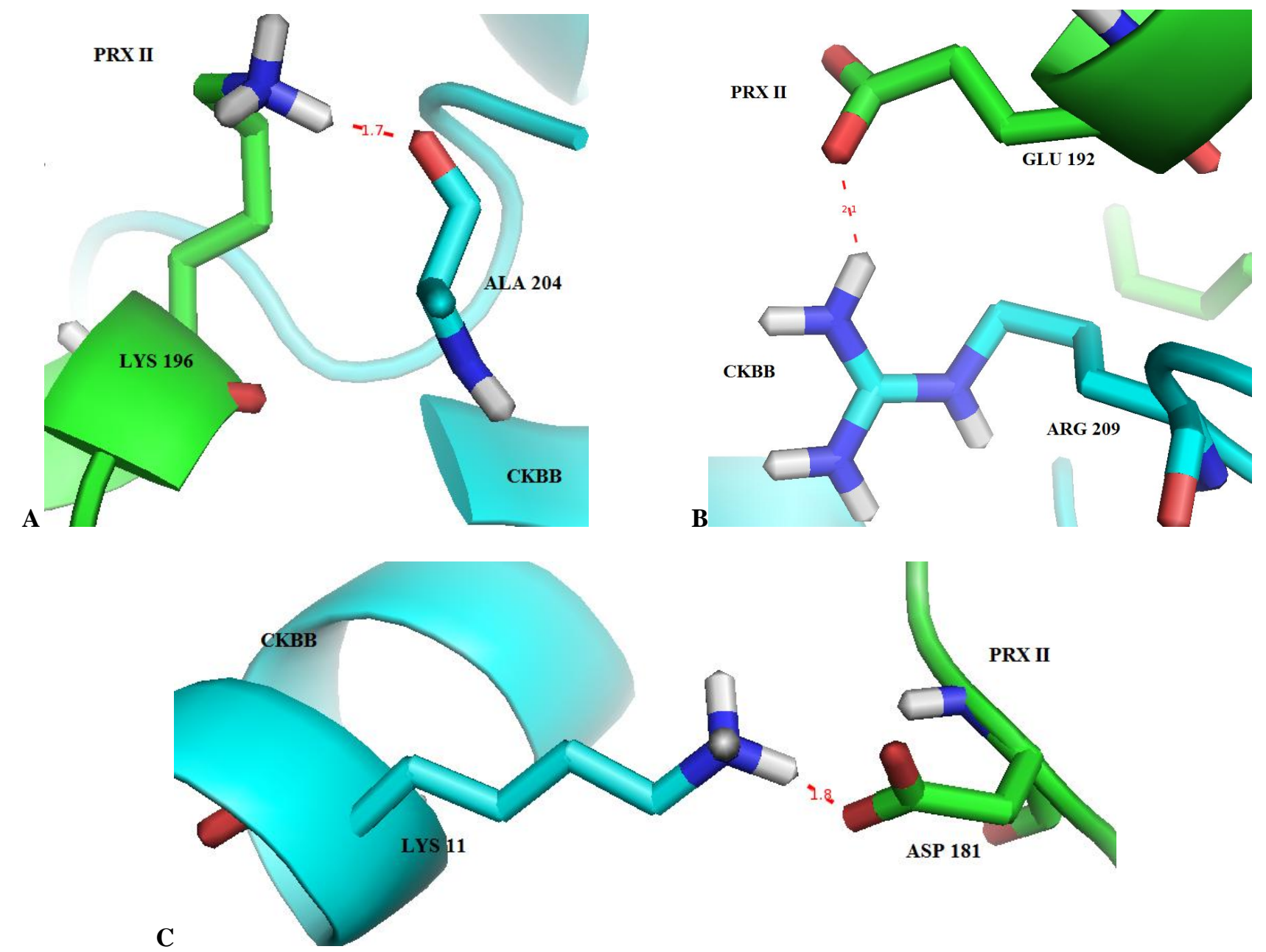

Fig. 2: The set of Prx II and CKBB interacting residues. Hydrogen bond and electrostatic interactions between two aminoacid residues is shown with its distances $(\AA)$. Where: grey - hydrogen, dark blue - nitrogen, and red - oxygen atoms.Distance between two aminoacids residue indicated by a dashed red line. Pictures created using PyMol molecular viewer software. 


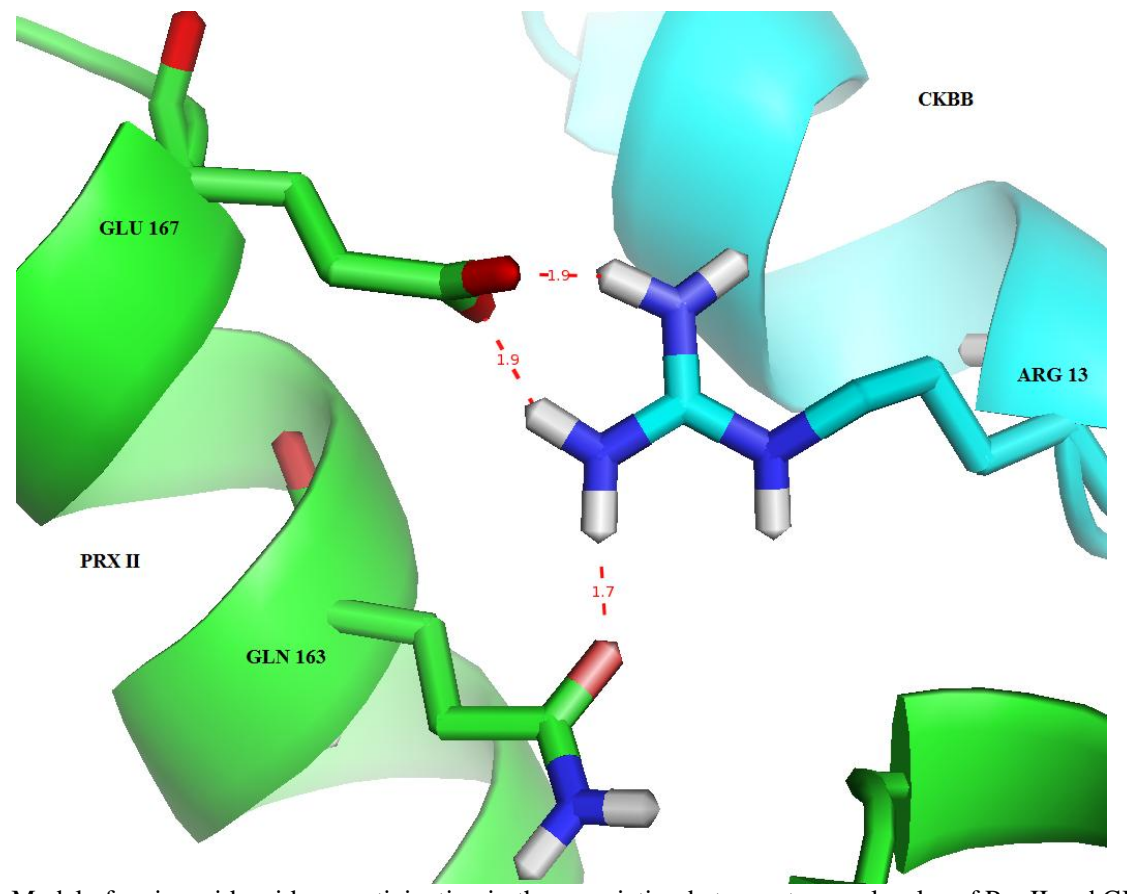

Fig. 3. Model of aminoacid residues participating in the association between two molecules of Prx II and CKBB.

Due to the remarkable structural rearrangements of Prx molecule, it is quite difficult to predict the exact interacting cluster of aminoacids with a partner protein. Although, a decameric state of peroxiredoxinis characterized as active, with reduced conserved cysteine residues, the equilibrium shifts right after the molecule of Prx has suffered the $\mathrm{H}_{2} \mathrm{O}_{2}$ triggered oxidation to a dimeric form with partial decameric presence (Barranco-Medina et al., 2008). Keeping in mind that under a severe hyperoxidationPrxs undergo a unique functional transformation from a low molecular weight species to a high molecular weight conglomerates. This conglomerates, that shaped as a long filament tubes, exhibit chaperonic activity by somehow attracting partner proteins into their custody. In our experiment we have seen, probably, a similar event, where the inactivated creatine kinase BB isoenzyme, which was identified by the coimmunoprecipitation assay as PrxII binding partner, interacted with hyperoxidized PrxII molecule at the specific aminoacid clusters. In this study, we could not verify the correctness of our results in vitro; it can be done by the site direct mutagenesis of interacting residues. Therefore, more studies are needed.

\section{CONCLUSION}

In this study, we have speculated that human Prx II and CKBB are the binding partners with definite aminoacid cluster of interaction. This fact was supported by the interaction simulation results using the online docking server ClusPro 2.0. By analyzing all ten generated models, we have come to conclusion that aminoacid residues of pivotal role are located in the $\mathrm{N}$-terminal region of CKBB (Lys 11, Arg 13) and the C-terminal region of Prx II (Asp 181, Glu 192, Lys 196). Therefore, discovered connection of human antioxidant enzyme, effective molecular chaperone Prx
II and a key regulator of ATP level in neural cells brain-type creatine kinase could contribute to more comprehensive understanding of the development of neurodegenerative processes in the human brain.

\section{REFERENCES}

Aksenov MY, Aksenova MV, Markesbery WR, Butterfield DA. Amyloid beta-peptide (1-40)-mediated oxidative stress in cultured hippocampal neurons. Protein carbonyl formation, CK BB expression, and the level $\mathrm{Cu}, \mathrm{Zu}$, and $\mathrm{Mn}$, SOD mRNA. Journal of Molecular Neuroscience, 1998; 10(3):181-192.

Aksenova MV, Aksenov MY, Payne RM, Trojanowski JQ, Schmidt ML, Carney JM, Butterfield DA, Markesbery WR. Oxidation of cytosolic proteins and expression of creatine kinase BB in frontal lobe in different neurodegenerative disorders. Dementia and Geriatric Cognitive Disorders, 1999; 10(2):158-165.

Barranco-Medina S, Kakorin S, Lazaro JJ, Dietz KJ. Thermodynamics of the dimer-decamer transition of reduced human and plant 2-cys peroxiredoxin. Biochemistry. 2008; 47(27):7196-7204.

Belousova LV, Muizhnek EL. Kinetics of chemical modification of arginine residues in mitochondrial creatine kinase from bovine heart: evidence for negative cooperativity. Biochemistry (Moscow), 2004; 69(4):455-461.

Bong SM, Moon JH, Nam KH, Lee KS, Chi Ym, Hwang KY. Structural studies of human brain-type creatine kinase complexed with the ADP-Mg2+-NO3-creatine transition-state analogue complex. FEBS Letters, 2008; 582(28):3959-3965

Camacho CJ, Gatchell DW, Kimura SR, Vajda S. Scoring docked conformations generated by rigid-body protein-protein docking. Protein: Structure, Function, and Bioinformatics, 2000; 40(3):525-537.

Comeau SR, Gatchell DW, Vajda S, Camacho CJ. ClusPro: an automated docking and discrimination method for the prediction of protein complexes. Bioinformatics, 2004; 20(1):45-50.

Choi MH, Lee IK, Kim GW, Kim BU, Han YH, Yu DY, Park HS, Kim KY, Lee JS, Choi C, Bae YS, Lee BI, Rhee SG, Kang SW. Regulation of PDGF signaling and vascular remodeling by peroxiredoxin II. Nature, 2005; 435(7040):347-357. 
Chen Y, Xu D. Computational analyses of high-throughput protein-protein interaction data. Current Protein and Peptide Science, 2003; 4(3):159-181.

Edminston PL, Schavolt KL, Kersteen EA, Moore NR, Borders CL. Creatine kinase: a role for arginine-95 in creatine binding and active site organization. BiochimicaetBiophysicaActa, 2001; 1546(2):291-298.

Gasteiger E, Hoogland C, Gattiker A, Duvaud S, Wilkins MR, Appel RD, Bairoch A. Protein identification and analysis tool on the ExPASy server. The Proteomics Protocols Handbook, 2005; 571-607.

Hall A, Karplus PA, Poole LB. Typical 2-Cys peroxiredoxins structures, mechanisms ad functions. FEBS Journal, 2009; 276(9):2469 2477.

Hall A, Nelson K, Poole LB, Karplus PA. Structure-based insights into the catalytic power and conformational dexterity of peroxiredoxins. Antioxidants and Redox Signaling, 2011; 15(3):795-815.

Hanschmann EM, Godoy JR, Berndt C, Hudemann C, Lillig $\mathrm{CH}$. Thioredoxins, glutaredoxins, and peroxiredoxins-molecular mechanism and health significance: from cofactors to antioxidants to redox signaling. Antioxidants and Redox Signaling, 2013; 19(13):15391605 .

Hensley K, Hall N, Subramaniam R, Cole P, Harris M, Aksenov M, Aksenova M, Gabbita SP, Wu JF, Carney JM, et al. Brain regional correspondence between Alzheimer's disease histopathology and biomarkers of protein oxidation. Journal of Neurochemistry, 1995; 65(5):2146-2156.

Hirotsu S, Abe Y, Okada K, Nagahara N, Hori H, Nishino T, Hakoshima T. Crystal structure of multifunctional 2-Cys peroxiredoxinheme-binding protein $23 \mathrm{kDa}$ /proliferation-associated gene product. Proceeding of the Natural Academy of Science, 1999; 96(2):12333-12338.

Jang HH, Lee KO, Chi YH, Jung BG, Park SK, Lee JR, Lee SS, Moon JC, Yun JW, Choi YO, Kim WY, Kang JS, Cheong GW, Yun DJ, Rhee SG, Cho MJ, Lee SY. Two enzymes in one; two yeast peroxiredoxins display oxidative stress-dependent switching from a peroxidase to a molecular chaperone function. Cell, 2004; 117(5):625-635.

Jung H, Kim T, Chae HZ, Kim KT, Ha H. Regulation of macrophage migration inhibitory factor and thiol-specific antioxidant protein PAG by direct interaction. The Journal of Biological Chemistry, 2001; 276(18):15504-15510.

Kim J, Amante DJ, Moody JP, Edgerly CK, Bordiuk OL, Smith K, Matson SA, Matson WR, Scherzer CR, Rosas HD, Hersch SM, Ferrante RJ. Reduced creatine kinase as a central and peripheral biomarker in Huntington's disease. BiochimicaetBiophysicaActa, 2010; 1802(78):673-681.

Kim SY, Kim TJ, Lee KY. A novel function of peroxiredoxin 1 (Prx-1) in apoptosis signal-regulating kinase 1 (ASK1)-mediated signaling pathway. FEBS Letters, 2008; 582(13):1913-1918.

Kozakov D, Beglov D, Bohnuud T, Mottarella SE, Xia B, Hall DR, Vajda S. How good is automated protein docking? Proteins: Structure, Function, and Bioinformatics, 2013; 81(12):2159-2166.

Lowther WT, Haynes AC. Reduction of cysteine sulfinic acid in eukaryotic, typical 2-Cys peroxiredoxins by sulfiredoxin. Antioxidant and Redox Signaling, 2011; 15(1):99-109.

Moon JC, Hah YS, Kim WY, Jung HH, Lee JR, Kim SY, Lee YM, Jeon MG, Kim CW, Cho MJ, Lee SY. Oxidative stress-dependent structural and functional switching of a human 2-Cys peroxiredoxinisotype II that enhances HeLa cell resistance to $\mathrm{H} 2 \mathrm{O} 2$-induced cell death. The Journal of Biological Chemistry, 2005; 280(31):28775-28784.

Mu ZM, Yin XY, Prochownik EV. Pag, a putative tumor suppressor, interacts with the Myc Box II domain of c-Myc and selectively alters its biological function and target gene expression. The Journal of Biological Chemistry, 2002; 277(45): 43175-43184.
Norel R, Sheinerman F, Petrey D, Honig B. Electrostatic contributions to protein-protein interactions: fact energetic filters for docking and their physical basis. Protein Science, 2001; 10(11):21472161 .

Qu D, Rashidian J, Mount MP, Aleyasin H, Parsanejad M, Lira A, Haque E, Zhang Y, Callaghan S, Daigle M, Rousseaux MW, Slack RS, Albert PR, Vincent I, Woulfe JM, Park DS. Role of Cdk5-mediated phosphorylation of Prx2 in MPTP toxicity and Parkinson's disease. Neuron, 2007; 55(1):37-52

Rakhmetov AD, Lee SP, Ostapchenko LI, Chae HZ. Analysis of creatine kinase activity with evaluation of protein expression under the effect of heat and hydrogen peroxide. The Ukrainian Biochemical Journal, $2015 ; 87(1): 75-82$.

Rhee SG, Woo HA. Multiple functions of peroxiredoxins: peroxidases, sensors and regulators of the intracellular messenger $\mathrm{H}_{2} \mathrm{O}_{2}$ and protein chaperone. Antioxidants and Redox Signaling, 2011; 15(3):781-794.

Saccoccia F, Di Micco P, Boumis G, Brunori M, Koutris I, Miele AE, Morea V, Sriratana P, Williams DL, Bellelli A, Angelucci F. Moonlighting by different stressors: crystal structure of the chaperone species of a 2-Cys peroxiredoxin. Structure, 2012; 20(3):429-39.

Schroder E, Littlechild JA, Lebedev AA, Errington N, Vagin AA, Isupov MN. Crystal structure of decameric 2-Cys peroxiredoxin from human erythrocytes at $1.7 \AA$ resolution. Structure, 2000; 8(6):605-615.

Tanaka K, Suzuki T. Role of amino-acid residue 95 in substrate specificity of phosphagen kinases. FEBS Letters, 2004; 573(1-3):78-82.

Tsai CJ, Xu D, Nussinov R. Structural motifs at protein-protein interfaces: protein cores versus two-state and three-state model complexes. Protein Science, 1997; 6(9):1793-1805.

Uda K, Suzuki T. Role of amino acids residues on the GS region of Stichopus arginine kinase and Danio creatine kinase. The protein Journal, 2004; 23(1):53-64.

Wallimann T, Tokarska-Schattner M, Schlattner U. The creatine kinase system and pleotropic effects of creatine. Amino Acids, 2011; 40(5):1271-1296.

Wood ZA, Schroder E, Robin Harris J, Poole LB. Structure, mechanism and regulation of peroxiredoxin. Trends in Biochemical Sciences, 2003; 28(1):32-40.

Wood TD, Guan Z, Borders CL, Chen LH, Kenyon GL, McLafferty FW. Creatine kinase: essential arginine residues at the nucleotide binding site identified by chemical modification and highresolution tandem mass spectrometry. Proceedings of the National Academy of Science. 1998; 95(7):3362-3365.

Yao J, Taylor M, Davey F, Ren Y, Aiton J, Coote P, Fang F, Chen JX, Yan SD, Gunn-Moore FJ. Interaction of amyloid binding alcohol dehydrogenase/Abeta mediates up-regalation of peroxiredoxin II in the brains of Alzheimer's disease patients and a transgenic Alzheimer's disease mouse model. Molecular and Cellular Neuroscience, 2007; 35(2):377-382.

Yao QZ, Zhou HM, Hou LX, Zou CG. A comparison of denaturation and inactivation rets of creatine kinase in guanidine solution. ScientiaSinica, 1982; 25(12):1296-1302.

How to cite this article:

Anar Rakhmetov, Sang Pil Lee, Dmytro Grebinyk, Ludmila Ostapchenko, Ho Zoon Chae., Simulation of Peroxiredoxin II and Brain-type Creatine Kinase protein-protein interaction using the online docking server ClusPro 2.0. J App Pharm Sci, 2015; 5 (08): 011-016. 